\title{
Focal uncaging of GABA reveals a temporally defined role for GABAergic inhibition during appetitive associative olfactory conditioning in honeybees
}

\author{
Davide Raccuglia ${ }^{1,2}$ and Uli Mueller ${ }^{1,3}$ \\ ${ }^{1}$ Department 8.3 Biosciences Zoology/Physiology-Neurobiology, ZHMB (Center of Human and Molecular Biology), Faculty \\ 8-Natural Science and Technology III, Saarland University, D-66041 Saarbrücken, Germany
}

\begin{abstract}
Throughout the animal kingdom, the inhibitory neurotransmitter $\gamma$-aminobutyric acid (GABA) is a key modulator of physiological processes including learning. With respect to associative learning, the exact time in which GABA interferes with the molecular events of learning has not yet been clearly defined. To address this issue, we used two different approaches to activate $\mathrm{GABA}$ receptors during appetitive olfactory conditioning in the honeybee. Injection of GABA-A receptor agonist muscimol 20 min before but not 20 min after associative conditioning affects memory performance. These memory deficits were attenuated by additional training sessions. Muscimol has no effect on sensory perception, odor generalization, and nonassociative learning, indicating a specific role of GABA during associative conditioning. We used photolytic uncaging of GABA to identify the GABA-sensitive time window during the short pairing of the conditioned stimulus (CS) and the unconditioned stimulus (US) that lasts only seconds. Either uncaging of GABA in the antennal lobes or the mushroom bodies during the CS presentation of the CS-US pairing impairs memory formation, while uncaging GABA during the US phase has no effect on memory. Uncaging GABA during the CS presentation in memory retrieval also has no effect. Thus, in honeybee appetitive olfactory learning GABA specifically interferes with the integration of CS and US during associative conditioning and exerts a modulatory role in memory formation depending on the training strength.
\end{abstract}

$\gamma$-Aminobutyric acid (GABA) is the most abundant inhibitory neurotransmitter and a key player in numerous physiological processes. In humans GABA-mediated inhibitory networks contribute to well-known physiological processes including anxiety (Sanders et al. 1995), sleep (Szymusiak and McGinty 2008), and memory formation (Paulsen and Moser 1998). The mammalian hippocampus, an essential structure for learning, is intensely innervated and modulated by GABAergic neurons (Klausberger 2009). Activation of GABA receptors in the hippocampus impairs learning, while blocking GABA receptors facilitates learning (Brioni et al. 1990; Zarrindast et al. 2002; Lasarge et al. 2009). However, the time window within which GABAergic transmission is interfering with molecular processes of learning and memory formation is still debated. While some studies differentiate between the early memory acquisition and the later consolidation phase regarding the effects of GABA agonists and antagonists (Rossato et al. 2004; Meyers et al. 2006; Rezayof et al. 2007), other studies argue that GABA plays an overall role in both processes (Brioni et al. 1989; Makkar et al. 2010). These discrepancies are most likely due to differences in the time of GABAergic drug injection and their diffusion within the tissue that leads to a vague temporal interference with GABA receptor activation (Chrobak et al. 1989; Harris and Westbrook 1999).

Recently, the basic role of GABAergic inhibition in memory formation has been confirmed by studies on associative learning in Drosophila (Liu et al. 2007; Liu and Davis 2009; Pitman et al. 2011; Wu et al. 2011). Insect mushroom bodies (MBs) that play

\footnotetext{
2Present address: Department of Cellular \& Molecular Physiology, Yale School of Medicine, New Haven, Connecticut 06520, USA ${ }^{3}$ Corresponding author

E-mail uli.mueller@mx.uni-saarland.de

Article is online at http://www.learnmem.org/cgi/doi/10.1101//m.030205.112.
}

a central role in learning are innervated by GABAergic neurons, which control neuronal activity and thus affect memory formation (Liu et al. 2007; Liu and Davis 2009; Pitman et al. 2011; Wu et al. 2011). Genetically enhanced GABAergic inhibition of MB circuitries impairs associative olfactory learning in Drosophila (Liu et al. 2007). Although these genetic manipulations are well designed to elucidate general wiring diagrams, they leave brain structures inaccessible regarding quick and flexible events such as transmitter actions within certain timeframes. GABA actions and its contributions to learning processes belong to the latter category.

In order to achieve a high temporal resolution of GABA receptor activation during associative learning, we used in vivo uncaging of GABA during olfactory associative conditioning of the proboscis extension response (PER) in the honeybee, Apis mellifera (Takeda 1961; Bitterman et al. 1983). The PER can be conditioned by a single pairing of an odor (conditioned stimulus, CS) with a sucrose reward (unconditioned stimulus, US) (Hammer and Menzel 1995). For the honeybee, it is well known that CS as well as US activates GABAergic neurons innervating the MBs (Gronenberg 1987; Grünewald 1999). After characterizing the time window in which the selective ionotropic GABA receptor agonist muscimol affects learning, we applied in vivo uncaging of GABA to address the temporal domain of GABA action on learning in detail.

\section{Results}

GABA receptor activation during memory acquisition impairs memory formation

To test whether activation of ionotropic GABA receptors affects memory formation, we injected the selective ionotropic GABA 
Table 1. Dose-dependent memory impairment after muscimol injection

\begin{tabular}{llll}
$\begin{array}{l}\text { Concentration } \\
\text { of injected } \\
\text { muscimol }\end{array}$ & PBS PER (2 h) & $\begin{array}{l}\text { Muscimol } \\
\text { PER (2 h) }\end{array}$ & \\
\hline $5 \mathrm{mM}$ & $69.6 \%(n=46)$ & $69.8 \%(n=53)$ & $\chi^{2}=0.04, P=1.00$ \\
$10 \mathrm{mM}$ & $77.5 \%(n=40)$ & $29.3 \%(n=41)$ & $\chi^{2}=17.0, P<0.001$ \\
$20 \mathrm{mM}$ & $71.1 \%(n=38)$ & $22.5 \%(n=40)$ & $\chi^{2}=16.6, P<0.001$ \\
\hline
\end{tabular}

Twenty minutes before single-trial training, bees (numbers in parentheses) were injected with muscimol at concentrations as indicated or with PBS. The data show the percentage of bees reacting to the conditioned odor (PER) $2 \mathrm{~h}$ after learning. Although $5 \mathrm{mM}$ muscimol has no effect on memory performance, 10 and $20 \mathrm{mM}$ muscimol lead to a significant impairment in memory performance $2 \mathrm{~h}$ after training as indicated by the $P$-values (Chisquare/Fisher's exact test, two-tailed).

agonist muscimol 20 min before conditioning. Although a concentration of $5 \mathrm{mM}$ had no effect, 10 and $20 \mathrm{mM}$ muscimol significantly impaired memory performance at $2 \mathrm{~h}$ (Table 1 ). In the following experiments, we used a concentration of $10 \mathrm{mM}$ muscimol to compare differential effects of GABA receptor activation on acquisition and/or consolidation of memory. We injected $10 \mathrm{mM}$ muscimol either $20 \mathrm{~min}$ before or $20 \mathrm{~min}$ after conditioning and handled all shown groups in parallel (Fig. 1). Muscimol injection before single-trial training disrupted memory performance at $2 \mathrm{~h}$ and $1 \mathrm{~d}$ after training $\left(2 \mathrm{~h}, \chi^{2}=17.0, P<0.001 ; 1 \mathrm{~d}, \chi^{2}=7.93, P=\right.$ 0.003) (Fig. 1A). Muscimol injection before three-trial training (Fig. 1B) did not affect memory acquisition (2. trial, $\chi^{2}=0, P=$ 0.83 ; 3. trial, $\chi^{2}=0.14, P=0.65$ ) or memory performance after $2 \mathrm{~h}\left(\chi^{2}=0.29, P=0.49\right)$, whereas memory performance $1 \mathrm{~d}$ after three-trial training was significantly impaired $\left(\chi^{2}=3.88, P=\right.$ 0.032). Muscimol injections after single-trial $\left(2 \mathrm{~h}, \chi^{2}=0.15, P=\right.$ 0.649; $\left.1 \mathrm{~d}, \chi^{2}=0.03, P=1\right)$ (Fig. $\left.1 \mathrm{C}\right)$ or three-trial training $(2 \mathrm{~h}$, $\chi^{2}=0.88, P=0.31 ; 1 \mathrm{~d}, \chi^{2}=0.01, P=0.83$ ) (Fig. 1D) had no impact on memory performance.

Previous work in insects demonstrates that inhibition of ionotropic GABA receptors increases odor generalization (Stopfer et al. 1997; Hosler et al. 2000). To test whether activation of ionotropic GABA receptors affects odor generalization, we performed a separate experiment and additionally tested a novel odor at 2-h memory retrieval (Table 2). Injection of muscimol 20 min before acquisition impairs odor-specific memory as tested by the odor used for conditioning but does not affect the PER to a new, novel odor. Injection of muscimol $20 \mathrm{~min}$ before 2-h memory retrieval neither affects memory performance nor odor generalization. This suggests that activation of GABA receptors and thus increased GABAergic inhibition during acquisition specifically affects processes of memory performance but not processes of odor coding.

To ensure that the impaired memory performance induced by muscimol during conditioning is not due to altered sucrose processing, we tested the gustatory sensitivity. Responsiveness tests revealed no difference between PBS and muscimol injected bees (Table 3). Also, muscimol had no effect on nonassociative learning paradigms like habituation or sensitization (Table 3), which demonstrates that there are no detectable deficits in the perception of the odor or reward alone. Together with the findings that GABA receptor activation during training, but not during memory consolidation, impairs memory formation, the results suggest that GABA plays a prominent role during CS-US pairing. To identify the exact time window in which muscimol interferes with CS and/or US processing by the activation of GABA receptors we uncaged GABA in vivo. This provided the possibility to determine a temporally and locally defined role for GABA during CS-US pairing.

\section{GABA immunoreactivity after uncaging GABA in vitro and in vivo}

To verify the uncaging protocol, photo-uncaging of GABA was tested in vitro. A solution containing $\alpha$-carboxy-2-nitrobenzyl (CNB)caged GABA was illuminated using a xenon flash lamp system (Fig. 2A). With an increasing number of light flashes applied to the CNB-GABA solution, the relative GABA immunoreactivity increased. The parallel handled glutamate solution showed basal GABA immunoreactivity irrespective of the number of flashes applied. This demonstrates the sufficiency of the flash lamp system to photo-release CNB-GABA in vitro and proves the selectivity of the antibody used. GABA release in vivo was quantified by ELISA measurements of brains and visualized by immunohistochemistry. The concentration of CNB-caged GABA used in this study was based on experience from earlier uncaging studies in honeybees (Müller 2000; Müller and Hildebrandt 2002; Locatelli et al. 2005). To prevent degradation of uncaged GABA in vivo and during the following preparation, the GABA reuptake inhibitor tiagabine was injected prior to the injection of CNB-GABA and the subsequent flash experiment. As compared to control brains (not flashed), photostimulation of brains significantly increased GABA immunoreactivity, demonstrating that the applied photostimulation protocol successfully releases GABA within the bee brain (Student's $t$-test, $d f=19.4, t=-2.17, P=0.043$ ) (Fig. 2B). Immunological staining of histological slices confirms the quantitative ELISA results. GABA-immunoreactivity in the MB of the stimulated brain side is increased as compared to that in the unstimulated side (Fig. 2C). Focal photostimulation of the MBs did not increase the immunostaining in the antennal lobes (ALs) of the same hemisphere, indicating that uncaging of GABA is locally restricted. This legitimizes the experimental application to activate $G A B A$ receptors in a defined local and temporal pattern during olfactory associative learning.
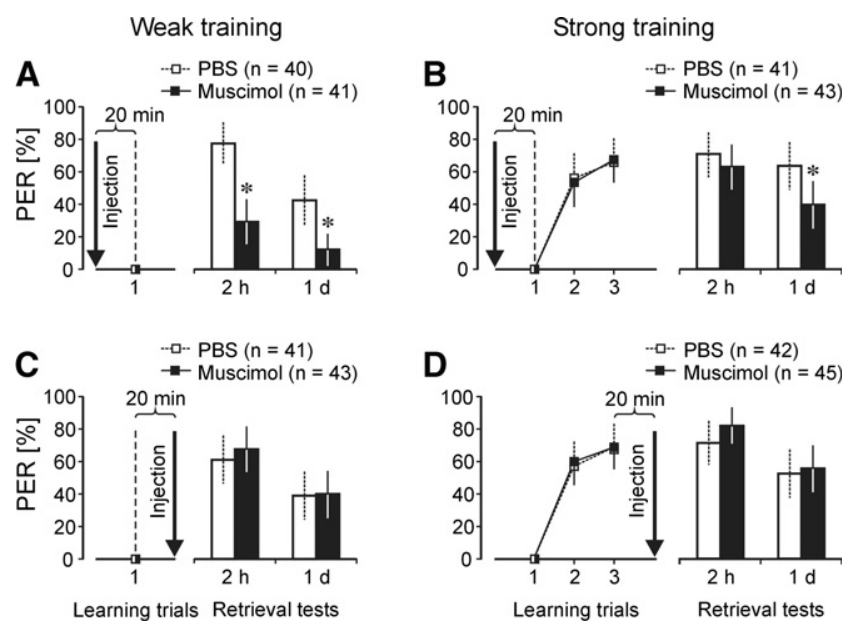

Figure 1. Muscimol injection before but not after learning impairs memory performance. Percentage of bees showing the PER to odor presentation during learning and subsequent retrieval tests performed $2 \mathrm{~h}$ and $1 \mathrm{~d}$ after learning. Animals were injected with muscimol, an activator for ionotropic GABA receptors, either before $(A, B)$ or after $(C, D)$ learning. Muscimol injection 20 min before single-trial training $(A)$ severely impaired memory retrieval $2 \mathrm{~h}$ and $1 \mathrm{~d}$ after learning. Muscimol injection 20 min before three-trial training $(B)$ only impaired memory retrieval after $1 \mathrm{~d}$. However, muscimol injections $20 \mathrm{~min}$ after single-trial $(C)$ or three-trial training $(D)$ had no effect on memory performance. Numbers in parentheses indicate number of animals used. The data represent total percentage of bees showing the PER, error bars indicate $95 \%$ binomial confidence interval (Chi-square/Fisher's exact test, $\left[{ }^{*}\right] P<0.05$, details in text). 
Table 2. Muscimol does not affect odor discrimination

\begin{tabular}{lrrr}
\hline Time of injection & PBS PER (2 h) & Muscimol PER (2 h) & \\
\hline 20 min before acquisition & CS $+: 90.0 \%(n=50)$ & CS $+: 68.9 \%(n=45)$ & $\chi^{2}=5.34, P=0.02$ \\
& NS: $30.0 \%(n=50)$ & NS: $26.7 \%(n=45)$ & $\chi^{2}=0.02, P=0.82$ \\
20 min before & CS $+: 82.6 \%(n=46)$ & CS $+: 73.8 \%(n=42)$ & $\chi^{2}=0.55, P=0.44$ \\
2-h retrieval test & NS: $10.9 \%(n=46)$ & NS: $14.3 \%(n=42)$ & $\chi^{2}=0.03, P=0.75$ \\
\hline
\end{tabular}

Bees (numbers in parentheses) were injected with muscimol $(10 \mathrm{mM})$ or PBS, either before training or before 2 -h retrieval test after single-trial training. Muscimol injected 20 min before acquisition significantly reduces PER to the conditioned odor (CS+) but does not alter PER to a novel stimulus (NS, 1-octanol). Muscimol injected 20 min before 2-h retrieval test neither affects memory performance to CS + nor to NS. In all cases, the PER elicited by CS + significantly differs from the PER elicited by NS (at least $\chi^{2}>14, P<$ 0.001). Chi-square/Fisher's exact test (two-tailed) was used for statistical comparison.

\section{Releasing GABA in $\mathrm{MB}$ or $\mathrm{AL}$ during CS-US pairing impairs olfactory learning}

The injection of muscimol in the behavioral experiments indicated that GABA receptors influence memory formation during acquisition (Fig. 1). Given the information that CS and US activate GABAergic neurons (Gronenberg 1987; Grünewald 1999), we focused our analysis on CS-US pairing during single-trial training (Fig. 3). Honeybees injected with CNB-GABA or PBS received flashes directed on the MBs at different time points during CS-US pairing. Uncaging GABA in the MBs directly after the CS-US pairing did not affect memory performance $\left(2 \mathrm{~h}, \chi^{2}=0.08, P=1 ; 1 \mathrm{~d}\right.$, $\left.\chi^{2}=0.6, P=0.44\right)$ (Fig. 3A). Uncaging GABA a few seconds before and during the CS presentation of CS-US pairing significantly impaired memory retrieval $2 \mathrm{~h}$ after learning $\left(2 \mathrm{~h}, \chi^{2}=4.61, P=\right.$ 0.023; $1 \mathrm{~d}, \chi^{2}=1.51, P=0.19$ ) (Fig. 3B). In order to prove that the observed memory impairment is not due to CNB-GABA injection, both groups were injected with CNB-GABA but only one group received UV-light flashes to the MBs (Fig. 3C). Only the photostimulated bees were significantly impaired in memory performance $2 \mathrm{~h}$ after learning $\left(2 \mathrm{~h}, \chi^{2}=5.44, P=0.013 ; 1 \mathrm{~d}, \chi^{2}=0.5\right.$, $P=0.39$ ). Bees receiving no UV-light pulses performed normally, indicating no toxicity of CNB-GABA.

Similar to uncaging GABA in the MBs, uncaging GABA in the ALs immediately before and during CS-US pairing impaired memory performance $2 \mathrm{~h}$ after learning $\left(2 \mathrm{~h}, \chi^{2}=3.92, P=\right.$ 0.032; $1 \mathrm{~d}, \chi^{2}=2.08, P=0.12$ ) (Fig. $4 \mathrm{~A}$ ). Uncaging GABA in the optic lobes (OLs) had no impact on olfactory learning $\left(2 \mathrm{~h}, \chi^{2}=\right.$ $0.02, P=0.76 ; 1 \mathrm{~d}, \chi^{2}=0.31, P=0.45$ ) (Fig. $4 \mathrm{~B}$ ), which confirms that photo-uncaging of GABA is locally restricted and does not spread to other brain regions such as the ALs or MBs.

The observation that photo-uncaging of GABA before and during, but not after, the CS presentation during conditioning affects memory performance argues for a role of GABAergic processes during associative learning. To test whether this GABA action is restricted to CS-US pairing or whether GABA release generally interferes with odor processing, we uncaged GABA before and during the CS presentation at the 2 -h retrieval test (Fig. 5). In this case, uncaging GABA in the MBs $\left(2 \mathrm{~h}, \chi^{2}=0.13, P=\right.$ $0.62 ; 1 \mathrm{~d}, \chi^{2}=0.01, P=1$ ) (Fig. 5A) or in the ALs $\left(2 \mathrm{~h}, \chi^{2}=1, P=0.3 ; 1 \mathrm{~d}\right.$, $\chi^{2}=0.04, P=1$ ) (Fig. 5B) did not affect memory performance, a result that clearly shows the specific role of GABA during CS-US association in ALs and MBs.

\section{Discussion}

We demonstrate that application of the GABA agonist muscimol during (but not after) appetitive olfactory conditioning of the PER impairs appetitive memory formation in the honeybee. By photorelease of GABA, we show that neuronal circuits in the ALs and the MBs are GABA-sensitive during a distinct time period of CS-US pairing. This adds new information to our knowledge on the role of GABA in memory formation that so far is mainly based on studies on aversive conditioning paradigms in Drosophila (Liu et al. 2007; Liu and Davis 2009) and mammals (Chapouthier and Venault 2002; Zarrindast et al. 2002; Makkar et al. 2010). This, together with our finding that GABA action is restricted to a few seconds in CS-US pairing, argues for a highly specific function of GABAergic transmission in associative conditioning irrespective of the learning paradigm.

In both Drosophila and honeybees, the ALs and the MBs are sites that critically contribute to associative olfactory learning (Hammer and Menzel 1998; Dubnau et al. 2001; Yu et al. 2004; Berry et al. 2008). Although in Drosophila a contribution of GABAergic input into the ALs to memory formation has not been described so far, our findings in honeybees argue for GABAsensitive neuronal circuits in the MBs and the ALs that both contribute to memory formation. Since studies in Drosophila focus on manipulations of GABA receptors in the MBs and the GABAergic anterior paired lateral (APL) neurons that innervate the MBs (Liu et al. 2007; Liu and Davis 2009; Pitman et al. 2011), a direct comparison, especially with regard to the role of the ALs, is difficult.

Although blocking the output of APL neurons and thus GABAergic input on MBs after appetitive olfactory conditioning disrupts labile memory in Drosophila (Pitman et al. 2011), we found no indication that manipulation of GABA transmission after the conditioning phase (muscimol and photo-release of GABA) affects memory in honeybees. Whether this difference is due to the distinct techniques used to manipulate GABA transmission or due to differences of the neuronal networks' contributions to the different learning paradigms remains to be tested.

Nevertheless, our observation that GABA specifically interferes with CS-US pairing in honeybees is consistent with the outcome of studies in Drosophila that monitor GABAergic input neurons, the APL neurons, and their target the MBs. Increasing GABAergic inhibition in the MBs of Drosophila causes weakening of odor-induced calcium signals, while US processing is unaffected (Liu et al. 2007). Moreover, immediately after a single CS-US pairing (but not CS or US alone), the APL neurons decrease their response to trained odors, which reduces their inhibitory action on neuronal circuits in the MBs and thus facilitates subsequent CS-US pairings (Liu et al. 2007; Liu and Davis 2009). Since the

Table 3. Muscimol injection neither affects gustatory sensitivity nor nonassociative learning

\begin{tabular}{lrrr}
\hline Behavioral test & \multicolumn{1}{c}{ PBS } & \multicolumn{1}{c}{ Muscimol } \\
\hline Gustatory sensitivity & $1.14(n=38)$ & $1.05(n=41)$ & $U=710, P=0.64$ \\
Habituation & $1 \pm 0.37(n=32)$ & $1.18 \pm 0.61(n=34)$ & $d f=55, t=1.47, P=0.15$ \\
Sensitization & $31.6 \%(n=38)$ & $23.1 \%(n=39)$ & $\chi^{2}=0.34, P=0.45$ \\
\hline
\end{tabular}

Bees (numbers in parentheses) were injected with muscimol $(10 \mathrm{mM})$ or PBS before testing gustatory sensitivity, habituation, or sensitization. Gustatory sensitivity: Values indicate the relation between the mean of the gustatory response score after and before injection. The gustatory response scores were compared by Mann-Whitney U-test. Habituation: Numbers of stimuli until habituation were normalized to the mean of the control group injected with PBS. Numbers of stimuli until habituation were compared using the Student's t-test (two-tailed). Sensitization: Percentages of sensitized bees were compared with Chi-square/ Fisher's exact test (two-tailed). 
A

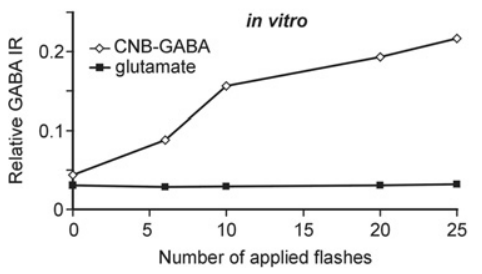

B

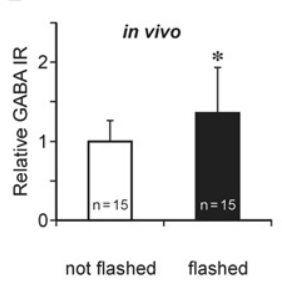

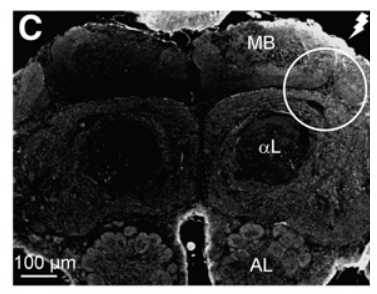

not flashed

flashed

Figure 2. Photo-uncaging of CNB-GABA determined in vitro and in vivo. $(A)$ Relative GABA immunoreactivity (GABA IR) in a CNB-GABA solution but not in a glutamate solution increases with number of applied flashes (details in Materials and Methods). ( $B, C)$ For in vivo measurement of released GABA, bees were given tiagabine and CNB-GABA injections directly into the brain. $(B)$ The columns show the means and standard deviations of relative GABA immunoreactivity (GABA IR) determined (ELISA) in the central brain of bees flashed either seven or zero (control) times before preparation. Relative GABA immunoreactivity in flashed bees is significantly increased ( $t$-test, $\left.\left[{ }^{*}\right] P<0.05\right)$ as compared to the not flashed control group. Numbers in the bars represent the number of animals measured. (C) For GABA immunohistology only the MB of the left brain side was flashed seven times in vivo. As indicated by the circle, the photostimulated area shows increased GABA-immunostaining in sections. $(\alpha \mathrm{L})$ $\alpha$-lobe.

properties of GABAergic feedback neurons in honeybees (Gronenberg 1987; Grünewald 1999) are similar to those in Drosophila, it is likely that photo-release of GABA overrides the conditioninginduced decrease in GABA release and thus impairs memory.

Interestingly, we find that GABA receptor activation during three-trial conditioning does not affect performance during acquisition or 2-h memory but impairs memory performance after $1 \mathrm{~d}$. A direct comparison with other studies is not possible because the influence of GABAergic inhibition on performance during acquisition has not yet been investigated in insects. However, studies in contextual fear-learning in rats find that GABA receptor activation during acquisition does not prevent the animals from learning the CS-US association but, rather, causes them to acquire a context-specific inhibitory association (CS-no US) that interferes with the actual association during consolidation (Harris and Westbrook 1999; Makkar et al. 2010). This hypothesis is consistent with our results, as we find that GABA acts during acquisition to impair memory formation but without affecting performance during acquisition.

Moreover, we find that memory formation is affected differently, depending on the acquired training strength during acquisition. As cAMP-dependent signaling processes contribute to the transition from short- to long-lasting memories (Müller 2000; Berry et al. 2008), an interaction between the cAMP-cascade and the function of GABA receptors is likely. Different studies demonstrate that phosphorylation of GABA receptors by cAMPdependent protein kinase (PKA) can cause a decrease in GABA mediated chloride influx or change the number and subunit composition of GABA receptors (McDonald et al. 1998; Jacob et al. 2008; Luscher et al. 2011). These interactions could explain how an increased PKA activation mediated by an intensified training strength attenuates memory deficits induced by muscimol injection. Thus, local interactions between PKA activation and GABAergic inputs in ALs and MBs during learning provide a molecular mechanism that modulates the impact of successive conditioning trials depending on their properties, such as stimulus strength and inter-trial interval.

\section{Materials and Methods}

\section{Animals}

Experiments were conducted year-round in Saarbrücken, Germany, using honeybees (Apis mellifera) of the University apiary. Foragers were caught in front of hives maintained outdoors in period of at least $16 \mathrm{~h}$. The training procedure was performed as described elsewhere (Müller 2002). An acquisition trial consisted of pairing an odor stimulus (clove oil) (CS, conditioned stimulus) with a sucrose reward (1 M) (US, unconditioned stimulus). The CS was delivered for $4 \mathrm{sec}$ using a 20-mL syringe with clove oil. Two seconds after the odor onset, the antennae were touched with a sucrose-moistened toothpick and the bees were allowed to lick sucrose for $\sim 3 \mathrm{sec}$. Weak training consisted of one CS-US pairing (single-trial). Strong training
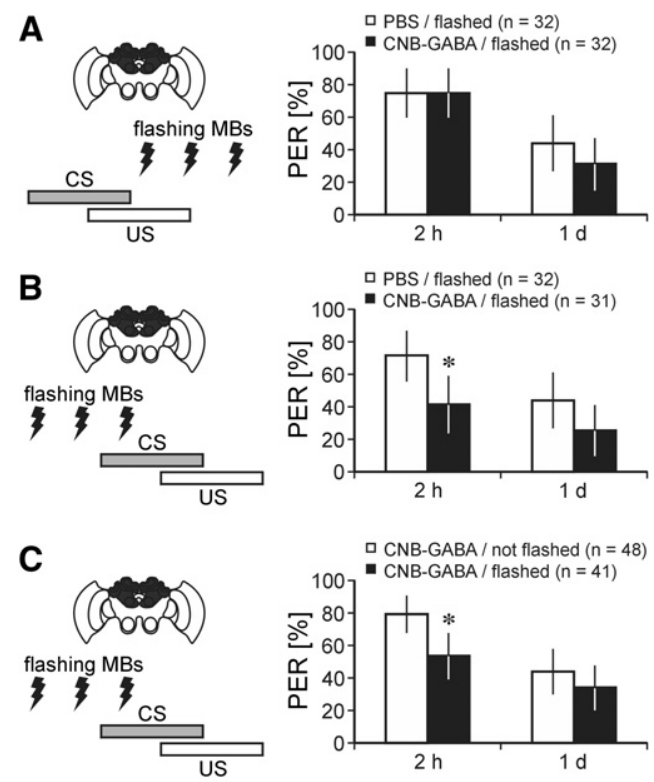

Learning trial

Retrieval tests

Figure 3. Local uncaging of GABA in MBs before and during CS-US pairing impairs memory performance. Twenty minutes before single-trial training bees received brain injections of CNB-GABA or PBS. The left panel indicates the targeted brain area, the flash symbols indicate time of uncaging (seven flashes within $12 \mathrm{sec}$ ) during CS-US presentation. The right panel displays percentage of bees that showed PER to odor presentation during retrieval tests performed $2 \mathrm{~h}$ and $1 \mathrm{~d}$ after training. Uncaging of GABA in MBs after CS $(A)$ had no impact on memory performance. Uncaging of GABA in MBs before and during $C S(B, C)$ impaired memory retrieval after $2 \mathrm{~h}$. Numbers in parentheses indicate number of animals tested. The data represent total percentage of bees showing the PER, error bars indicate $95 \%$ binomial confidence interval (Chi-square/ Fisher's exact test, $[*] P<0.05$, details in text). 
A
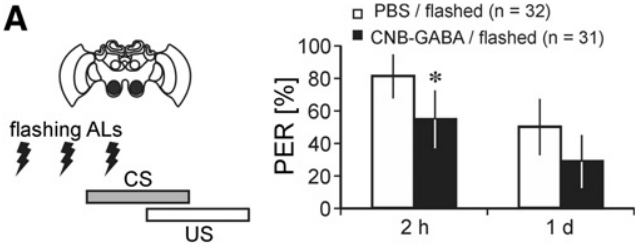

B

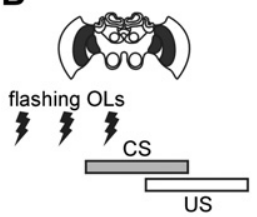

Learning trial

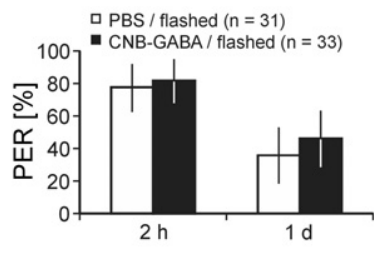

Retrieval tests

Figure 4. Memory performance is impaired after local uncaging of GABA in ALs before and during CS-US pairing. Using the same protocol as in Figure 3 GABA was uncaged in either $\mathrm{ALs}(A)$ or OLs $(B)$ as indicated in the left panel. (A) Memory impairment was observed when ALs were flashed before and during CS. (B) Uncaging GABA in the OLs before and during CS does not affect memory. Numbers in parentheses indicate number of animals tested. The data represent total percentage of bees showing the PER, error bars indicate $95 \%$ binomial confidence interval (Chi-square/Fisher's exact test, $\left[{ }^{*}\right] P<0.05$, details in text).

consisted of three CS-US pairings (three-trial) with an inter-trial interval (ITI) of $2 \mathrm{~min}$. For memory recall, only the CS was presented to the bees. For 2-h and 1-d memory recall, the same bees were tested. Odor generalization was tested for 2-h memory recall (Table 2). Each animal was tested with the conditioned odor (clove oil) and a novel odor (1-octanol) applied in a random sequence. An exhaust eliminated lingering odor. Bees showing a PER to odor presentation or that did not react with a PER to US presentation during the first CS-US pairing were excluded from further evaluation $(<5 \%)$.

\section{Gustatory sensitivity}

To test whether the injections influenced the processing of appetitive stimuli, we monitored the PER after touching the antennae with gradually increasing sucrose concentrations $(0 \mathrm{M}, 30 \mathrm{mM}$, $100 \mathrm{mM}, 300 \mathrm{mM}$, and $1 \mathrm{M}$ ) using moistened toothpicks (Friedrich et al. 2004; Scheiner 2004). Each single bee was tested before and 30 min after drug injection. Bees showing no PER to $1 \mathrm{M}$ sucrose before drug injection were excluded from further evaluation $(5 \%-$ $10 \%$ ). For each bee, the total number of proboscis responses to the five gustatory stimuli ( $0-1 \mathrm{M}$ sucrose) was summed up (scores from 0 to 5). This value reflects the "gustatory response score" (Scheiner et al. 2001), which can be used to compare the gustatory sensitivity of individuals before and after treatment.

\section{Habituation}

Habituation of the PER was tested by repeatedly touching one antenna with a sucrose-moistened toothpick (1 M sucrose). A bee is considered habituated when showing no PER during five consecutive sucrose stimuli. Following habituation, the contralateral antenna was touched to test for dishabituation (Müller and Hildebrandt 2002). Bees showing no PER at dishabituation were excluded from further evaluation $(<5 \%)$.

\section{Sensitization}

Spontaneous reaction to odors was tested using clove oil as described elsewhere (Hammer et al. 1994). Two minutes after the odor stimulus bees were sensitized by antennal stimulation with sucrose $(1 \mathrm{M})$. Twenty seconds after sensitization the odor was presented for a second time. During this second presentation, the PER was monitored. Bees showing the PER to the initial odor stim-

ulus or showing no PER during sucrose stimulation were excluded from further evaluation $(5 \%-10 \%)$.

\section{Muscimol injections}

One day prior to behavioral experiments, bees were mounted in plastic tubes, the heads were fixed with wax, and the lens of the median ocellus was cut out. At times indicated in Results, a volume of $0.2 \mu \mathrm{L}$ muscimol in PBS (10 mM; Ascent Scientific) or PBS $\left(137 \mathrm{mM} \mathrm{NaCl}, 2.7 \mathrm{mM} \mathrm{KCl}, 10.1 \mathrm{mM} \mathrm{Na}_{2} \mathrm{HPO}_{4}, 1.8 \mathrm{mM}\right.$ $\mathrm{KH}_{2} \mathrm{PO}_{4}$ ) was injected into the median ocellus using a pulled glass capillary (Bio-Logic) connected to a microinjector (Pikospritzer II, General Valve). Substances injected into the median ocellus (Mercer and Menzel 1982) follow the main ocellar tract and are rapidly distributed throughout the entire brain (Menzel et al. 1999).

\section{Uncaging experiments}

One day prior to behavioral experiments, bees were mounted in tubes, the heads were fixed with wax, and a window was cut into the head capsule. Bees with yellow glands covering the brain and blocking flash illumination of the brain were omitted from the experiments $(\sim 25 \%)$. A JML-C2 flash lamp system (Rapp OptoElectronic $\mathrm{GmbH}$ ) generated high-power light pulses (10-msec pulse, $220 \mathrm{~J}$ at source, spectrum between 250 and 1000 $\mathrm{nm}$ ) used for photostimulation. A $625-\mathrm{nm}$ pass filter limited the light bandwidth. The flash output entered the photo adapter port of the binocular microscope (Leica). Self-made masks in the focusing plane allowed discrete photostimulation of the desired brain regions (Müller 2000). Twenty minutes prior to photostimulation, the bees were injected with $0.1-\mu \mathrm{L}$ CNB-caged GABA in PBS (20 mM; Invitrogen) or PBS into each brain hemisphere. Since the efficiency of uncaging in vivo cannot be calculated, the concentration of CNB-caged GABA used in this study was based on experience from earlier uncaging studies in honeybees (Müller 2000; Müller and Hildebrandt 2002; Locatelli et al. 2005).

\section{Determination of GABA immunoreactivity using ELISA}

The successful release of GABA was measured by standard ELISA protocol (Crowther 2000) using an antibody that specifically recognizes GABA-glutardialdehyde conjugates (mouse, 1:1000; Sigma-Aldrich).

In vitro measurement: $50-\mu \mathrm{L}$ CNB-GABA $(1 \mathrm{mM})$ or glutamate $(1 \mathrm{mM})$ (control) were flashed in Eppendorf tubes $(0,5,10$,
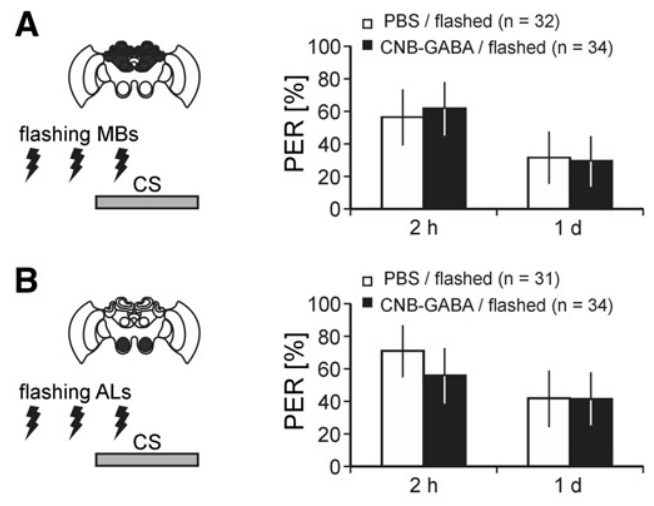

$2 \mathrm{~h}$ retrieval test

Figure 5. Local uncaging of GABA before and during CS presentation of retrieval test at $2 \mathrm{~h}$ does not impair retrieval. Twenty minutes before 2 -h $\mathrm{h}$ retrieval tests bees received brain injections of CNB-GABA or PBS. GABA was uncaged (seven flashes within $12 \mathrm{sec}$ ) before and during CS presentation of the 2-h retrieval test (left panel). Neither uncaging in MBs $(A)$ nor in ALs (B) had significant effect on memory retrieval. Numbers in parentheses indicate number of animals tested. The data represent total percentage of bees showing the PER, error bars indicate $95 \%$ binomial confidence interval (Chi-square/Fisher's exact test, $\left[{ }^{*}\right] P<0.05$, details in text). 
20, 25 times; 2-sec interval between flashes). After photo-uncaging, $10 \mu \mathrm{L}$ glutardialdehyde (25\%), $50 \mu \mathrm{g}$ BSA, and $440 \mu \mathrm{L}$ PBS were added, followed by 1 -h incubation at $6^{\circ} \mathrm{C}$. Conjugation was stopped by adding $50 \mu \mathrm{L} 100 \mathrm{mM}$ Tris (pH 7). Probes were diluted for standard ELISA protocol.

In vivo measurement: A window was cut into the head capsule as described for the uncaging experiments. The GABA reuptake inhibitor tiagabine $(0.1 \mu \mathrm{L}, 10 \mathrm{mM}$; Ascent Scientific) was injected into each brain hemisphere $40 \mathrm{~min}$ before photostimulation. Twenty minutes later, $0.1 \mu \mathrm{L}$ CNB-caged GABA $(20 \mathrm{mM}$, Invitrogen) was injected into each brain hemisphere. In the photostimulated group, the central brain was illuminated with seven light flashes (2-sec interval between flashes), while the control group was not illuminated. Subsequently, the central brain was dissected and homogenized in $200 \mu \mathrm{L}$ PBS containing $1 \mathrm{M}$ urea and $1 \mathrm{mM}$ EDTA. To each sample $(50 \mu \mathrm{L}), 10 \mu \mathrm{L}$ glutardialdehyde and $12 \mu \mathrm{g}$ BSA were added and incubated for $1 \mathrm{~h}$ at $6^{\circ} \mathrm{C}$. Conjugation was stopped by adding $50 \mu \mathrm{L}$ Tris (100 mM, pH 7). The relative amount of GABA immunoreactivity was determined by ELISA. To compensate for the size of the prepared tissue the GABA value of each sample was normalized to PKA-R2 immunoreactivity (Müller 1997).

\section{Immunohistology}

As described for the determination of GABA immunoreactivity in vivo, $0.1 \mu \mathrm{L}$ tiagabine $(10 \mathrm{mM}$; Ascent Scientific) was injected into each brain hemisphere. CNB-caged GABA $(0.1 \mu \mathrm{L}, 20 \mathrm{mM}$; Invitrogen) was consecutively injected $20 \mathrm{~min}$ before the $\mathrm{MB}$ of the left hemisphere was photostimulated seven times (see Fig. 2C). Directly after photostimulation, the head capsule was flooded with fixing solution (PBS containing $0.5 \%$ paraformaldehyde and $1.25 \%$ glutardialdehyde) and incubated for $30 \mathrm{~min}$ at room temperature. The bee brain was dissected and incubated in fixing solution for an additional $2.5 \mathrm{~h}$ at $4^{\circ} \mathrm{C}$. The tissue was dehydrated in increasing grades of isopropyl alcohol (60\%-100\%) and subsequently infiltrated and embedded in paraffin for sectioning. The sections $(7 \mu \mathrm{m})$ were mounted on poly-L-lysine slides and subsequently rehydrated, starting with xylene followed by decreasing grades of ethanol $(100 \%-50 \%)$. Prior to antibody application, slides were blocked with blocking solution (PBS containing $0.1 \%$ Triton 100 and $0.5 \%$ BSA) for $30 \mathrm{~min}$ at room temperature. GABA antibody (mouse, 1:1000, diluted in blocking solution; Sigma-Aldrich) was applied to the sections and incubated overnight at $4^{\circ} \mathrm{C}$. The sections were washed $(3 \times 5 \mathrm{~min})$ in PBS containing $0.1 \%$ Triton and incubated for $1.5 \mathrm{~h}$ at room temperature with Cy3-conjugated anti-mouse IgG (Goat; Dianova) diluted 1:500 in blocking solution. Sections were washed in PBS containing $0.1 \%$ Triton and mounted in a glycerol-aqua mix (1:1). The image was taken using an Axiovert 200M microscope (Zeiss) with a Zeiss 20X Plan-Neofluar objective (NA 0.3) and a cooled CCD camera (Cool Snap $\mathrm{HQ}^{2}$; Photometrics). Dorsal and ventral parts of the brain were photographed separately as 24-bit RGB pictures and subsequently converted to one 8-bit grayscale picture with a resolution of $300 \mathrm{dpi}$.

\section{Statistical analysis}

SYSTAT10 was used for the statistical analysis. Habituation (Table 3) and relative GABA immunoreactivity (Fig. 2B) were compared with Student's $t$-tests (independent samples, unequal sample variances, two-tailed). The responsiveness scores were compared by Mann-Whitney $U$-test. The Chi-square/Fisher's exact test was used for pairwise comparison of the behavioral data (PER). For each comparison, we indicated the Yates value (corrected for continuity) together with the Fisher's exact probability (two-tailed). In all cases, $P<0.05$ is considered as significant.

\section{Acknowledgments}

We thank Angelika Gardezi for excellent technical assistance, Dr. Michael Kunst for helpful comments, and Dr. Susanne Meuser for invaluable discussions and comments.

\section{References}

Berry J, Krause WC, Davis RL. 2008. Olfactory memory traces in Drosophila. Prog Brain Res 169: 293-304.

Bitterman ME, Menzel R, Fietz A, Schafer S. 1983. Classical olfactory conditioning of proboscis extension in honeybees. J Comp Physiol 97: $107-119$.

Brioni JD, Nagahara AH, McGaugh JL. 1989. Involvement of the amygdala GABAergic system in the modulation of memory storage. Brain Res 487: $105-112$.

Brioni JD, Decker MW, Gamboa LP, Izquierdo I, McGaugh JL. 1990. Muscimol injections in the medial septum impair spatial learning. Brain Res 522: 227-234.

Chapouthier G, Venault P. 2002. GABA-A receptor complex and memory processes. Curr Top Med Chem 2: 841-851.

Chrobak JJ, Stackman RW, Walsh TJ. 1989. Intraseptal administration of muscimol produces dose-dependent memory impairments in the rat. Behav Neural Biol 52: 357-369.

Crowther JR. 2000. The ELISA guidebook. Methods in molecular biology, 149: III-IV, 1-413. Humana Press, Clifton, NJ.

Dubnau J, Grady L, Kitamoto T, Tully T. 2001. Disruption of neurotransmission in Drosophila mushroom body blocks retrieval but not acquisition of memory. Nature 411: 476-480.

Friedrich A, Thomas U, Müller U. 2004. Learning at different satiation levels reveals parallel functions for the cAMP-protein kinase A cascade in formation of long-term memory. J Neurosci 24: 4460-4468.

Gronenberg W. 1987. Anatomical and physiological properties of feedback neurons of the mushroom bodies in the bee brain. Exp Biol 46: $115-125$.

Grünewald B. 1999. Physiological properties and response modulations of mushroom body feedback neurons during olfactory learning in the honeybee, Apis mellifera. J Comp Physiol A 185: 565-576.

Hammer M, Menzel R. 1995. Learning and memory in the honeybee. J Neurosci 15: 1617-1630.

Hammer M, Menzel R. 1998. Multiple sites of associative odor learning as revealed by local brain microinjections of octopamine in honeybees. Learn Mem 5: 146-156.

Hammer M, Braun G, Mauelshagen J. 1994. Food-induced arousal and nonassociative learning in honeybees: Dependence of sensitization on the application site and duration of food stimulation. Behav Neural Biol 62: $210-223$.

Harris JA, Westbrook RF. 1999. The benzodiazepine midazolam does not impair Pavlovian fear conditioning but regulates when and where fear is expressed. J Exp Biol 25: 236-246.

Hosler JS, Buxton KL, Smith BH. 2000. Impairment of olfactory discrimination by blockade of GABA and nitric oxide activity in the honey bee antennal lobes. Behav Neurosci 114: 514-525.

Jacob TC, Moss SJ, Jurd R. 2008. GABA(A) receptor trafficking and its role in the dynamic modulation of neuronal inhibition. Nat Rev Neurosci 9: $331-343$.

Klausberger T. 2009. GABAergic interneurons targeting dendrites of pyramidal cells in the CA1 area of the hippocampus. Eur J Neurosci 30: $947-957$

Lasarge CL, Banuelos C, Mayse JD, Bizon JL. 2009. Blockade of GABA(B) receptors completely reverses age-related learning impairment. Behav Neurosci 164: 941-947.

Liu X, Davis RL. 2009. The GABAergic anterior paired lateral neuron suppresses and is suppressed by olfactory learning. Nat Neurosci 12: 53-59.

Liu X, Krause WC, Davis RL. 2007. GABAA receptor RDL inhibits Drosophila olfactory associative learning. Neuron 56: 1090-1102.

Locatelli F, Bundrock G, Müller U. 2005. Focal and temporal release of glutamate in the mushroom bodies improves olfactory memory in Apis mellifera. J Neurosci 25: 11614-11618.

Luscher B, Fuchs T, Kilpatrick CL. 2011. GABAA receptor traffickingmediated plasticity of inhibitory synapses. Neuron 70: 385-409.

Makkar SR, Zhang SQ, Cranney J. 2010. Behavioral and neural analysis of GABA in the acquisition, consolidation, reconsolidation, and extinction of fear memory. Neuropsychopharmacology 35: 1625-1652.

McDonald BJ, Amato A, Connolly CN, Benke D, Moss SJ, Smart TG. 1998. Adjacent phosphorylation sites on GABAA receptor $\beta$ subunits determine regulation by cAMP-dependent protein kinase. Nat Neurosci 1: $23-28$.

Menzel R, Heyne A, Kinzel C, Gerber B, Fiala A. 1999. Pharmacological dissociation between the reinforcing, sensitizing, and responsereleasing functions of reward in honeybee classical conditioning. Behav Neurosci 113: 744-754.

Mercer AR, Menzel R. 1982. The effects of biogenic amines on conditioned and unconditioned responses to olfactory stimuli in the honeybee Apis mellifera. J Comp Physiol 145: 363-368.

Meyers RA, Zavala AR, Speer CM, Neisewander JL. 2006. Dorsal hippocampus inhibition disrupts acquisition and expression, but not 
consolidation, of cocaine conditioned place preference. Behav Neurosci 120: $401-412$.

Müller U. 1997. Neuronal cAMP-dependent protein kinase type II is concentrated in mushroom bodies of Drosophila melanogaster and the honeybee Apis mellifera. J Neurobiol 33: 33-44.

Müller U. 2000. Prolonged activation of cAMP-dependent protein kinase during conditioning induces long-term memory in honeybees. Neuron 27: $159-168$.

Müller U. 2002. Learning in honeybees: From molecules to behaviour. Zoology (Jena) 105: 313-320.

Müller U, Hildebrandt H. 2002. Nitric oxide/cGMP-mediated protein kinase A activation in the antennal lobes plays an important role in appetitive reflex habituation in the honeybee. J Neurosci 22: $8739-8747$.

Paulsen O, Moser EI. 1998. A model of hippocampal memory encoding and retrieval: GABAergic control of synaptic plasticity. Trends Neurosci 21: $273-278$.

Pitman JL, Huetteroth W, Burke CJ, Krashes MJ, Lai SL, Lee T, Waddell S. 2011. A pair of inhibitory neurons are required to sustain labile memory in the Drosophila mushroom body. Curr Biol 21: 855-861.

Rezayof A, Razavi S, Haeri-Rohani A, Rassouli Y, Zarrindast MR. 2007. GABA(A) receptors of hippocampal CA1 regions are involved in the acquisition and expression of morphine-induced place preference. Eur Neuropsychopharmacol 17: 24-31.

Rossato JI, Bonini JS, Coitinho AS, Vianna MR, Medina JH, Cammarota M, Izquierdo I. 2004. Retrograde amnesia induced by drugs acting on different molecular systems. Behav Neurosci 118: 563-568.
Sanders SK, Morzorati SL, Shekhar A. 1995. Priming of experimental anxiety by repeated subthreshold GABA blockade in the rat amygdala. Brain Res 699: 250-259.

Scheiner R. 2004. Responsiveness to sucrose and habituation of the proboscis extension response in honey bees. J Comp Physiol 190: 727-733.

Scheiner R, Page RE Jr, Erber J. 2001. Responsiveness to sucrose affects tactile and olfactory learning in preforaging honey bees of two genetic strains. Behav Brain Res 120: 67-73.

Stopfer M, Bhagavan S, Smith BH, Laurent G. 1997. Impaired odour discrimination on desynchronization of odour-encoding neural assemblies. Nature 390: 70-74.

Szymusiak R, McGinty D. 2008. Hypothalamic regulation of sleep and arousal. Ann N Y Acad Sci 1129: 275-286.

Takeda K. 1961. Classical conditioned response in the honey bee. J Insect Physiol 58: 168-179.

Wu CL, Shih MF, Lai JS, Yang HT, Turner GC, Chen L, Chiang AS. 2011. Heterotypic gap junctions between two neurons in the Drosophila brain are critical for memory. Curr Biol 21: 848-854.

Yu D, Ponomarev A, Davis RL. 2004. Altered representation of the spatial code for odors after olfactory classical conditioning; memory trace formation by synaptic recruitment. Neuron 42: 437-449.

Zarrindast MR, Bakhsha A, Rostami P, Shafaghi B. 2002. Effects of intrahippocampal injection of GABAergic drugs on memory retention of passive avoidance learning in rats. J Psychopharmacol 16: 313-319.

Received December 22, 2012; accepted in revised form May 14, 2013. 


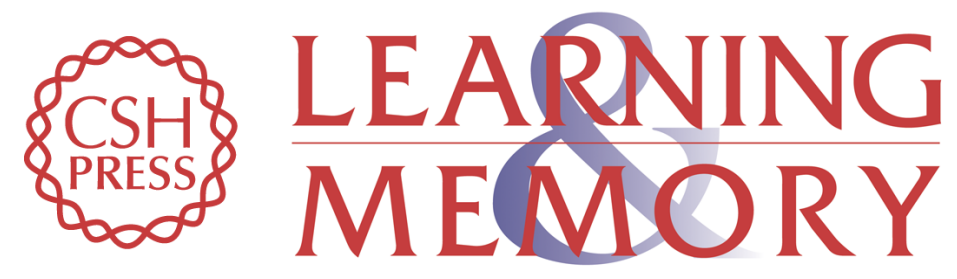

\section{Focal uncaging of GABA reveals a temporally defined role for GABAergic inhibition during appetitive associative olfactory conditioning in honeybees}

Davide Raccuglia and Uli Mueller

Learn. Mem. 2013, 20:

Access the most recent version at doi:10.1101//m.030205.112

References This article cites 45 articles, 5 of which can be accessed free at: http://learnmem.cshlp.org/content/20/8/410.full.html\#ref-list-1

Creative This article is distributed exclusively by Cold Spring Harbor Laboratory Press for the Commons first 12 months after the full-issue publication date (see

License http://learnmem.cshlp.org/site/misc/terms.xhtml). After 12 months, it is available under a Creative Commons License (Attribution-NonCommercial 3.0 Unported), as described at http://creativecommons.org/licenses/by-nc/3.0/.

Email Alerting Receive free email alerts when new articles cite this article - sign up in the box at the Service top right corner of the article or click here. 